\title{
O ENSINO DE PROJETO INTEGRADO DE AROUITETURA E URBANISMO E A MUDANÇA NO HABITUS
}

\author{
Daniel Medeiros de Freitas ${ }^{1}$
}

DOI: 10.5752/P.2316-1752.2017v24n35p70

\begin{abstract}
Resumo
A necessária integração conceitual e instrumental entre o projeto de edificações e o planejamento do espaço urbano é, de um lado, um desafio recorrente no debate sobre a formação dos arquitetos urbanistas. Por outro lado, o contexto de intensificação da ação do capital sobre a forma urbana em diferentes frentes, sobretudo por meio de Grandes Projetos Urbanos, demanda a problematização da forma urbana autoral e fechada e o modo como esta é abordada na estrutura curricular dos cursos de graduação em arquitetura e urbanismo. Este artigo se insere nessa lacuna por meio da análise da disciplina Projeto Integrado de Arquitetura e Urbanismo, na qual os alunos desenvolvem intervenção construída na interface entre o campo da arquitetura e do planejamento urbano. Foram analisados registros das bancas de avaliação e o memorial descritivo dos projetos,
\end{abstract}

\footnotetext{
1. Arquiteto pela PUC Minas, especialista, mestre e doutor em Urbanismo pela UFMG. Professor do Departamento de Urbanismo da Escola de Arquitetura da UFMG. E-mail: danielmedeirosdefreitas@gmail.com
} 
complementados por notas de aula ao longo de experiência docente na disciplina entre 2012 e 2015. A análise recorre ao conceito bourdiano de habitus, com ênfase no papel desse tipo de disciplina na sua construção e consolidação. $\mathrm{O}$ artigo aponta as dificuldades de integração entre escalas e discute como essa situação pode estar contribuindo, em vez de reverter, para a produção de projetos arquitetônicos cada vez mais desarticulados com a leitura do lugar, de formas urbanas fechadas, espetacularizadas e reprodutoras dos processos de acumulação e segregação socioespacial.

Palavras-chave: Projeto integrado de arquitetura e urbanismo. Ensino de projeto. Projeto de arquitetura. Planejamento urbano. Desenho urbano. 


\section{TEACHING ARCHITECTURE AND URBANISM INTEGRATED PROJECT AND THE CHANGE OF HABITUS}

\begin{abstract}
The conceptual and instrumental integration between building design and urban space planning is a recurring challenge in the debate about the training of architects. On the other hand, the intensification of capital action over urban form, on different fronts, especially through Large Scale Urban Projects, demands the problematization of the project of urban forms in the curricular structure of the courses degree in architecture and urbanism. The article explores this gap through the analysis of the discipline Integrated Project of Architecture and Urbanism, in which the students develop intervention built in the interface between the field of architecture and urban planning. In order to do so, we analyzed the records of the evaluation banks and the descriptive memorial of the projects, complemented by lecture notes throughout the teaching experience in the discipline between 2012 and 2015. The analysis uses the Bourdian concept of habitus, with an emphasis on the role of this type discipline in its construction and consolidation. The article points out the difficulties of integration between scales and discusses how this situation may be contributing, instead of reversing, to the production of architectural projects increasingly disarticulated with the reading of the place, and of urban forms closed, spectacularized and reproductive of the processes accumulation and socio-spatial segregation.
\end{abstract}

Keywords: Integrated Project of Architecture and Urbanism. Architecture project studio. Arban planning. Urban design.

\section{LA ENSEÑANZA DE DISEÑO INTEGRADO DE ARQUITECTURA Y URBANISMO Y EL CAMBIO EN EL HABITUS}

\section{Resumen}

La necesaria integración conceptual e instrumental entre el proyecto de edificaciones y la planificación del espacio urbano es un desafío recurrente en el debate sobre la formación de los arquitectos urbanistas. Por otro lado, el contexto de intensificación de la acción del capital sobre la forma urbana, en diferentes frentes, sobre todo por medio de Grandes Proyectos Urbanos, demanda la problematización de la forma urbana autoral y cerrada y el modo en que ésta es abordada en la estructura curricular de los cursos de graduación en arquitectura y urbanismo. El artículo se inserta en esa laguna por medio del análisis de la disciplina Proyecto Integrado de Arquitectura y Urbanismo, en la cual los alumnos desarrollan intervención construida en la interfaz entre el campo de la arquitectura y la planificación urbana. Para ello, se analizaron los registros de las bancas de evaluación y el memorial descriptivo de los proyectos, complementados por notas de clase a lo largo de experiencia docente en la disciplina entre 2012 y 2015. El análisis recurre al concepto bourdiano de habitus, con énfasis en el papel de ese tipo de disciplina en su construcción y consolidación. El artículo apunta las dificultades de integración entre escalas y discute cómo esa situación puede estar contribuyendo, en vez de revertir, a la producción de proyectos arquitectónicos cada vez más desarticulados con la lectura del lugar, y de formas urbanas cerradas, espectacularizadas y reproductores de los procesos de acumulación y segregación socio espacial.

Palabras-claves: Proyecto Integrado de Arquitectura y Urbanismo. Estudio de proyecto de arquitectura. Planificación urbana. Diseño urbano. 


\section{Introdução}

No Brasil, as diretrizes curriculares do curso de graduação em Arquitetura e Urbanismo enfatizam o perfil generalista do profissional "com relação à concepção, à organização e à construção do espaço interior e exterior, abrangendo o urbanismo, a edificação, o paisagismo, bem como a conservação e a valorização do patrimônio construído, a proteção do equilíbrio do ambiente natural e a utilização racional dos recursos disponíveis" (BRASIL, 2006). Tal recomendação se materializa em uma formação e atuação profissional que, em diversos momentos, persegue a construção de articulações entre campos disciplinares complexos, incluindo o da tecnologia construtiva, da produção do espaço urbano, da economia, da política, do meio ambiente e da cultura.

Desenvolve-se aqui uma reflexão localizada na interface entre a experiência docente na disciplina Projeto Integrado de Arquitetura e Urbanismo (PIAU) - voltada para a aproximação entre os campos do projeto arquitetônico e do planejamento urbano - e uma pesquisa dedicada a desvelar o campo de poder que estrutura a produção dos Grandes Projetos Urbanos (GPU) - setor da produção do espaço urbano no qual essa questão se materializa em maior intensidade e contradição. Sobre este último aspecto, a pesquisa define o conceito de GPU e o papel dos agentes de projeto e planejamento da seguinte forma: 
Grandes Projetos Urbanos são rupturas na produção do tecido urbano, concebidas como formas fechadas, em escala superior à tradicionalmente praticada no local, gerando, através de hegemonia do projeto em detrimento do plano de longo prazo, objetos icônicos que abrigam atividades restritas e homogêneas. Estes objetos são determinados por heranças históricas agravadas por recentes inflexões na economia global e pelo alinhamento entre Estado e capital, contexto permeado por paradigmas hegemônicos de produção da forma urbana e mediado por um grupo de agentes, cuja hierarquia é estruturada pelo atendimento a estas mesmas determinações. Agentes de planejamento urbano, mais do que escravos desse contexto, têm papel fundamental na sua manutenção e, portanto, na produção de formas urbanas que inviabilizam uma cidade justa. No entanto, ao mesmo tempo, são os agentes que potencialmente mais poderiam contribuir para sua desestabilização e resistência (FREITAS, 2016, p.362).

Sobre a disciplina PIAU, o artigo retoma notas e reflexões recolhidas em sala de aula entre 2012 e 2015 para avançar no debate sobre os desafios e limitações de integração entre os campos de arquitetura e urbanismo, considerando tanto os aspectos internos a cada campo quanto os aspectos relacionais entre os campos e destes com outros campos determinantes da forma urbana. Nesse percurso se dará maior destaque ao papel dos arquitetos e urbanistas de prática projetual e à caracterização do conceito bourdiano do habitus desses agentes (BOURDIEU, 1996; 2004). Importa identificar o modo como esse habitus vem sendo 
consolidado ao longo da formação acadêmica dos alunos para ser, mais tarde, modificado diante de situações, restrições e escolhas tomadas ao longo da vida profissional, resultando de uma combinação entre a formação acadêmica, a biografia social e a herança cultural de cada agente.

O conceito de habitus descreve o sistema de disposições socialmente adquiridas (produzidas pela interiorização das estruturas sociais) na experiência prática do indivíduo, orientadas para sua ação dentro do campo. Essas disposições, mais flexíveis que determinísticas, funcionam como uma espécie de princípio unificador entre agentes (ou grupos de agentes), que, no espaço social de diferenciações, retraduz a posição no campo de poder em um conjunto de escolhas. Dito de outra forma, o habitus seria uma "racionalidade prática adquirida mediante interação social" (THIRY-CHERQUES, 2006), que se converte em um princípio de ação estruturado, e ao mesmo tempo estruturador, da interação entre agentes.

A reflexão está organizada em três partes. A primeira discute a experiência docente por meio da proposição de uma classificação das abordagens e reações dos alunos ao problema colocado pela disciplina, destacando os pontos de conflito e os critérios projetuais e de avaliação. A segunda parte sistematiza e contextualiza a integração entre os campos disciplinares da arquitetura e o do urbanismo, tal 
como se apresentam na disciplina e na maior parte dos cursos de graduação em arquitetura e urbanismo brasileiros. A terceira parte retoma o conceito de habitus e o papel central que exerce na necessária construção de novas posturas de projeto da forma urbana e arquitetônica.

\section{Experiência de integração entre arquitetura e urbanismo}

A disciplina PIAU possui formato inspirado em tradicional estúdio/ateliê de projeto, em que quatro professores - dois do departamento de urbanismo e dois do departamento de projeto - orientam um tema conformado pela articulação entre uma situação urbana e um programa de atividades, da qual resulta uma intervenção ao mesmo tempo urbana e arquitetônica. Nos semestres que motivaram essa discussão foram trabalhados os seguintes temas: inserção de equipamento cultural em terreno do município de Rio Acima-MG no primeiro semestre de 2013; intervenção e edificação na região do Parque de Exposições da Gameleira em Belo Horizonte MG no segundo semestre de 2013 e primeiro semestre de 2014; e inserção de uma Estação Multimodal no bairro São José, Belo Horizonte-MG, no segundo semestre de 2014 e primeiro semestre de 2015.

A disciplina explora tanto as interfaces conceituais entre o campo da arquitetura e o do urbanismo quanto instrumen- 
tais, ou seja, as capacitações necessárias para transpor o diálogo do plano das ideias para soluções projetuais. Para tal, e esse pode ser considerado um dos primeiros conflitos observados, os docentes buscam equilibrar a tensão entre a definição de um restrito conjunto de produtos mínimos exigidos (percepções de campo, diagnósticos setoriais, plano de intervenções e projetos arquitetônicos) com um amplo leque de possibilidades analíticas e propositivas importadas do contato dos alunos com outras disciplinas, entre outras práticas como práticas de gestão, ativismo, urbanismo tático, interfaces tecnológicas e práticas extensionistas.

Com o objetivo de construir um retrato do cotidiano da disciplina, o Quadro 1 sintetiza uma classificação formulada a partir de seis situações-tipo recorrentes, atrelando as estratégias formuladas pelos alunos, os produtos resultantes e os critérios de avaliação. Como pode ser observado, os trabalhos são formulados por meio de duas etapas, uma primeira, em grupo de quatro alunos, da qual resulta o plano urbano de intervenções; e uma segunda, em dupla, da qual resulta o detalhamento da intervenção em escala urbana e arquitetônica. Em tempo, a avaliação é o momento principal de legitimação das capacidades de articulação e produção do aluno, no qual ele acumula ou perde capital cultural objetivado, testa seu capital corporificado e confirma ou tece parte de suas redes sociais, conforme será 
retomado na terceira parte deste artigo. Os símbolos (+) e (-) indicam a qualidade e/ou pertinência do produto em relação ao que é usualmente demandado em cada fase da disciplina, afetando a avaliação definida pelos docentes ao longo de três bancas intermediárias.

\begin{tabular}{|c|c|c|c|c|c|c|c|}
\hline \multicolumn{2}{|r|}{ ITEM ANALISADO } & \multicolumn{2}{|c|}{$\begin{array}{c}\text { PLANO MESTRE A } \\
\text { (Grupo com duas duplas) }\end{array}$} & \multicolumn{2}{|c|}{$\begin{array}{c}\text { PLANO MESTRE B } \\
\text { (Grupo com duas duplas) }\end{array}$} & \multicolumn{2}{|c|}{$\begin{array}{c}\text { PLANO MESTRE C } \\
\text { (Grupo com duas duplas) }\end{array}$} \\
\hline \multicolumn{2}{|c|}{ Conceito urbano } & \multicolumn{2}{|c|}{$\begin{array}{l}\text { Alunos consideram } \\
\text { necessária a criação de } \\
\text { uma centralidade a partir } \\
\text { do desenvolvimento da } \\
\text { economia, atração de } \\
\text { novos investidores } \theta \\
\text { parâmetros urbanos mais } \\
\text { permissivos como } \\
\text { estratégia. }\end{array}$} & \multicolumn{2}{|c|}{$\begin{array}{l}\text { Alunos consideram que a } \\
\text { questão central é a falta } \\
\text { de qualidade dos } \\
\text { espaços públicos de } \\
\text { convivio, o alto impacto } \\
\text { da especulação } \\
\text { imobiliária em curso e a } \\
\text { má soluçăo do sistema } \\
\text { viário de conexăo } \\
\text { regional. }\end{array}$} & \multicolumn{2}{|c|}{$\begin{array}{l}\text { Os alunos consideram que o } \\
\text { bairro possui vitalidade, } \\
\text { ameaçada pela } \\
\text { desarticulaçāo entre as } \\
\text { grandes obras viárias } \\
\text { recentes e o favorecimento } \\
\text { da especulação imobiliária. A } \\
\text { solução estaria na } \\
\text { identificaçăo e reativaçăo de } \\
\text { redes de economia local. }\end{array}$} \\
\hline \multirow{4}{*}{ 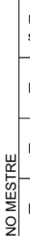 } & $\begin{array}{l}\text { Uso e ocupação do } \\
\text { solo }\end{array}$ & \multicolumn{2}{|c|}{$\begin{array}{l}\text { Delimita área de maior } \\
\text { adensamento }(+) \text { e com } \\
\text { fachada viva }(+/-) \text {. }\end{array}$} & \multicolumn{2}{|c|}{$\begin{array}{l}\text { Mantém coeficiente (-) e } \\
\text { cria área de estimulo a } \\
\text { determinados usos (+). }\end{array}$} & \multicolumn{2}{|c|}{$\begin{array}{l}\text { Cria parâmetro para fachadas } \\
\text { vivas }(+) \text { e comércio local }(+) \text {. }\end{array}$} \\
\hline & Dinâmica imobiliária & \multicolumn{2}{|c|}{$\begin{array}{l}\text { Faz analogia da região } \\
\text { com operaçōes urbanas } \\
\text { sem estudar local (-). }\end{array}$} & \multicolumn{2}{|c|}{$\begin{array}{l}\text { Identifica tendência } \\
\text { imobiliária e busca } \\
\text { reverter }(+) \text {. }\end{array}$} & \multicolumn{2}{|c|}{$\begin{array}{l}\text { Critica a especulação, mas } \\
\text { năo identifica agentes (-). }\end{array}$} \\
\hline & Perfil da populaçâo & \multicolumn{2}{|c|}{$\begin{array}{l}\text { Identifica baixa renda (+), } \\
\text { mas năo avalia potencial } \\
\text { gentrificaçăo }(-) \text {. }\end{array}$} & \multicolumn{2}{|c|}{$\begin{array}{l}\text { Identifica perfil de renda } \\
(+) \text {, associa com tipologia } \\
(+), \text { mas não propōe }(-)\end{array}$} & \multicolumn{2}{|c|}{$\begin{array}{l}\text { Identifica redes (+), perfil } \\
\text { comercial }(+) \text { e percepçăo } \\
\text { moradores }(+) \text {. }\end{array}$} \\
\hline & Legislaçăo urbana & \multicolumn{2}{|c|}{$\begin{array}{l}\text { Adensamento (-) e cita, } \\
\text { sem analisar, as } \\
\text { Operaçōes Urbanas (-). }\end{array}$} & \multicolumn{2}{|c|}{$\begin{array}{l}\text { Delimita ADE (+), mas } \\
\text { năo define diretrizes (-). } \\
\text { Adota lei vigente (-). }\end{array}$} & \multicolumn{2}{|c|}{$\begin{array}{l}\text { Não altera legislaçã̃o (-) e } \\
\text { propõe participacăo sem } \\
\text { definir modelo }(-) \text {. }\end{array}$} \\
\hline \multirow[t]{3}{*}{ a } & Sistema viário & \multicolumn{2}{|c|}{$\begin{array}{l}\text { Grandes obras de } \\
\text { infraestrutura de alto } \\
\text { impacto (-). }\end{array}$} & \multicolumn{2}{|c|}{$\begin{array}{l}\text { Poucas obras com maior } \\
\text { beneficio }(+) \text {. Não } \\
\text { discute modais }(-) \text {. }\end{array}$} & \multicolumn{2}{|c|}{$\begin{array}{l}\text { Dá privilégio ao pedestre }(+) \text {, } \\
\text { mas nâo resolve conflito } \\
\text { viărio }(-) \text {. }\end{array}$} \\
\hline & Meio Ambiente & \multicolumn{2}{|c|}{$\begin{array}{l}\text { Intervençōes estruturais } \\
\text { de grande escala }(+) \text {. }\end{array}$} & \multicolumn{2}{|c|}{$\begin{array}{l}\text { Areas de preservação (+) } \\
\text { e recuperaçăo; } \\
\text { hidrografia original (+). }\end{array}$} & \multicolumn{2}{|c|}{$\begin{array}{l}\text { Identificaçāo de áreas vazias } \\
(+) \text { e de preservação }(+) \text {. }\end{array}$} \\
\hline & Obras análogas & \multicolumn{2}{|c|}{$\begin{array}{l}\text { Operação urbana em } \\
\text { contexto diferente }(-) \text {. }\end{array}$} & \multicolumn{2}{|c|}{$\begin{array}{l}\text { Grande edificio com } \\
\text { mesmo programa (+). }\end{array}$} & \multicolumn{2}{|c|}{$\begin{array}{l}\text { Urbanismo tático } \\
\text { descontextualizado }(+) \text {. }\end{array}$} \\
\hline \multicolumn{2}{|r|}{ ITEM ANALISADO (resumo) } & DUPLA A1 & DUPLA A2 & DUPLA B1 & DUPLA B2 & DUPLA C1 & DUPLA C2 \\
\hline \multicolumn{2}{|r|}{ Projeto de espaço urbano } & $\begin{array}{l}\text { Formalista } \\
(-) \text { e sem } \\
\text { detalhe }(-)\end{array}$ & $\begin{array}{l}\text { Limitado } \\
\text { ao lote }(-) \\
\text { projeto }(+)\end{array}$ & $\begin{array}{l}\text { Parque e } \\
\text { entorno } \\
\text { bons }(+)\end{array}$ & $\begin{array}{l}\text { Somente } \\
\text { entorno (-) }\end{array}$ & $\begin{array}{c}\text { Boas } \\
\text { intervençcóes } \\
\text { pontuais }(+) \\
\end{array}$ & $\begin{array}{c}\text { Intervenções } \\
\text { de má } \\
\text { qualidade (-) }\end{array}$ \\
\hline \multicolumn{2}{|c|}{ Projeto de arquitetura } & $\begin{array}{l}\text { Boa } \\
\text { setorizaçāo } \\
\text { e forma }(+)\end{array}$ & $\begin{array}{l}\text { Detalhado } \\
(+) \text { bem } \\
\text { inserido } \\
(+)\end{array}$ & $\begin{array}{l}\text { Boa } \\
\text { setorizaçāo } \\
\text { e forma }(+)\end{array}$ & $\begin{array}{l}\text { Mal } \\
\text { resolvido } \\
(+)\end{array}$ & $\begin{array}{l}\text { Fragmentado } \\
\text { em açōes } \\
\text { pontuais }(+)\end{array}$ & $\begin{array}{c}\text { Pontual, mas } \\
\text { mal } \\
\text { resolvido (-) }\end{array}$ \\
\hline \multicolumn{2}{|r|}{ Conceito arquitetônico } & $\begin{array}{l}\text { Projeto } \\
\text { isolado (-) }\end{array}$ & $\begin{array}{l}\text { Definido } \\
\text { pelo } \\
\text { entorno (+) }\end{array}$ & $\begin{array}{l}\text { Projeto } \\
\text { estratégico } \\
(+)\end{array}$ & $\begin{array}{l}\text { Definido } \\
\text { pelo } \\
\text { entorno } \\
(+)\end{array}$ & $\begin{array}{c}\text { Potencializar } \\
\text { ocorrências } \\
(+)\end{array}$ & $\begin{array}{l}\text { Projeto } \\
\text { isolado }(-)\end{array}$ \\
\hline \multicolumn{2}{|c|}{$\begin{array}{l}\text { Avaliação (conceito) } \\
\text { Ver justificativa. }\end{array}$} & c & B & A & B & A & c \\
\hline
\end{tabular}

Quadro 1 | Seis situações-tipo observadas na disciplina PIAU.

Fonte: Elaborado pelo autor. 
Considerando a capacidade dos alunos de articular, no curto espaço de um semestre, as questões conceituais e instrumentais, a avaliação das seis situações-tipo de projeto poderia ser justificada da seguinte forma: a dupla A1 teve desempenho ruim na disciplina, porque parte de um instrumento desenvolvimentista sem problematizar seus efeitos e, embora chegue ao fechamento da equação de viabilidade e desenvolva um bom projeto de arquitetura, peca na inserção urbana equivocada e no projeto de espaços externos de transição limitada entre o objeto e seu local de inserção; a dupla A2 parte do mesmo conceito urbano e também ignora os efeitos do instrumento operação urbana, no entanto, mesmo atuando em escala limitada de projeto urbano, consegue entender as condicionantes locais no partido arquitetônico e avança no detalhamento de um projeto bem inserido no entorno; já a dupla B1 parte de um plano mestre mediano, que entende a área, mas não os instrumentos para sua modificação e chega a um bom projeto urbano e arquitetônico que, pelo caráter estratégico, consegue compensar a deficiência do plano urbano; a dupla B2 parte do mesmo plano urbano, mas avança pouco no projeto, embora compreenda o papel do lugar na concepção da arquitetura; finalmente, a dupla C1 parte de um bom conceito urbanístico e domínio crítico, mas possui pouco conhecimento sobre o cotidiano do planejamento urbano, ainda que, na etapa de projeto, apresente produtos compatíveis com o conceito. A dupla C2 parte do mesmo 
referencial de plano mestre, mas não consegue dar materialidade (ou produto equivalente) às diretrizes, recaindo, com atraso, na solução arquitetônica de qualidade insuficiente e isolada do entorno.

Ainda que o exercício acima, descolado do detalhamento dos casos que geraram a tipificação apresentada, assuma um caráter demasiadamente abstrato para aprofundar a discussão projetual, é possível utilizá-lo como indicador para a dificuldade dos estudantes em reagir aos desafios de uma integração que, ao longo da formação, Ihes é oferecida de modo desarticulado e com sombreamentos, descontinuidades e hiatos, argumento desenvolvido a seguir.

\section{Desafios da integração conceitual e instrumen-} tal

A tradição generalista dos cursos de Arquitetura e Urbanismo estrutura o currículo de modo a abranger, ao mesmo tempo, o ensino de uma prática, o ensino de uma reflexão sobre essa prática e o ensino dos campos disciplinares próximos. Nessa conformação, pode-se dizer que, grosso modo, as disciplinas orbitam entre dois polos: o objeto arquitetônico e o objeto urbano, ora de modo direto (ensino de projeto e análise da cidade, etc.) ora de modo complementar (cálculo estrutural, conforto ambiental, topografia, teoria urbana etc.), abrangendo um amplo conteúdo con- 


\section{ceitual e instrumental. O Quadro 2 sistematiza o conteú- do mais diretamente mobilizado pelo escopo da disciplina PIAU a partir da escala de intervenção.}

\begin{tabular}{|c|c|c|}
\hline Escala & Interfaces conceituais & Interfaces instrumentais \\
\hline $\begin{array}{l}\text { Escala da } \\
\text { edificaçăo }\end{array}$ & 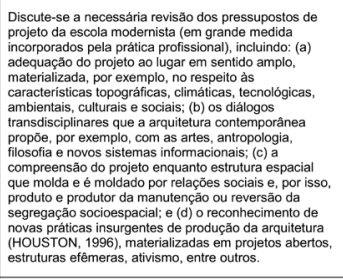 & 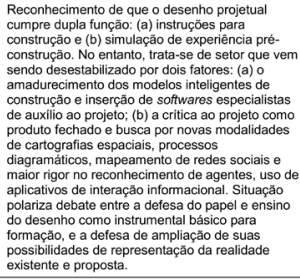 \\
\hline $\begin{array}{l}\text { Escala do } \\
\text { desenho } \\
\text { urbano e do } \\
\text { paisagismo }\end{array}$ & 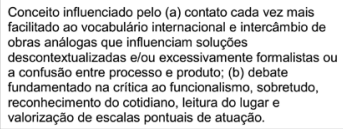 & $\begin{array}{l}\text { A representaçăo é agravada pela falta de } \\
\text { compreensaã e manipulaçâo da topografia, } \\
\text { representação de espaços externos e limitado } \\
\text { conhecimento de soluçôs técnicas para projeto } \\
\text { paisagistico, limitaçóes que condicionam opção } \\
\text { pelo abandono do desenho técnico nesta escala } \\
\text { e, mais grave, limita as estratégias de projeto sem } \\
\text { propor métodos e espaços de qualidade. }\end{array}$ \\
\hline $\begin{array}{l}\text { Escala do } \\
\text { projeto de } \\
\text { espaço urbano }\end{array}$ & 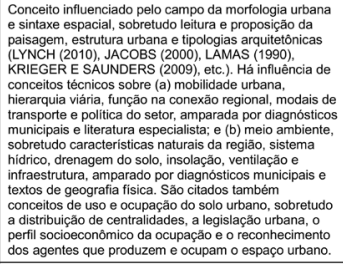 & 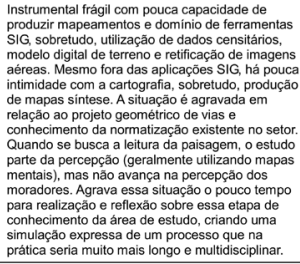 \\
\hline $\begin{array}{l}\text { Escala do } \\
\text { planejamento } \\
\text { urbano }\end{array}$ & 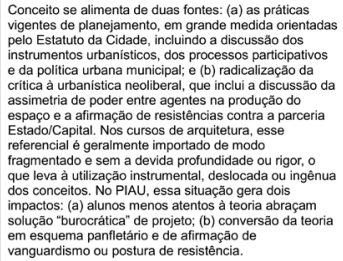 & $\begin{array}{l}\text { O planejamento urbano demanda um tipo } \\
\text { especifico de instrumentação voltado para o } \\
\text { entendimento e aplicação de instrumentos } \\
\text { técnicos de uso e ocupação do solo urbano } \\
\text { (parâmetros urbanisticos para construçoses, } \\
\text { operações urbanas, estimulo a usos do solo, } \\
\text { intervençôes no sistema viário, estudos de } \\
\text { impacto ambiental e de vizinhança, entre outros) } \\
\text { que exige compreensão de suas motivaçóes, } \\
\text { crítica e capacidade de aplicação, aspectos que } \\
\text { os alunos dominam de modo desigual e, quase } \\
\text { sempre, desvinculados de experiência prática. }\end{array}$ \\
\hline
\end{tabular}

Quadro 2 | Problemas de interface conceitual e instrumental de acordo com a escala de projeto. Fonte: Elaborado pelo autor. 
A desigual assimilação e manipulação dos conceitos e do instrumental resulta em um conjunto de desafios a ser enfrentado ao longo da disciplina PIAU, sistematizados a seguir por meio da seguinte sequência: (a) o posicionamento inicial do aluno em relação aos referenciais conceituais da teoria urbana e inserção do objeto arquitetônico; (b) a elaboração do plano urbano de intervenções; (c) o projeto do espaço urbano; (d) o projeto do espaço arquitetônico.

Inicialmente, sobre o posicionamento em relação à teoria urbana e arquitetônica, a observação do discurso dos alunos em bancas e memoriais descritivos permite identificar as posturas apresentadas no Quadro 3. Esse posicionamento inicial do aluno, mesmo quando não sistematizado por ele durante a fase inicial do processo de projeto, possui grande influência sobre as diretrizes iniciais do plano urbano e, consequentemente, sobre o diálogo que o objeto arquitetônico terá com a área de intervenção. Nesse sentido, trata-se de uma opção inicial, pouco problematizada, que pode alimentar a ruptura entre os dois campos e entre edifício e cidade. 


\begin{tabular}{|c|c|}
\hline Posicionamento em relação à teoria urbana & $\begin{array}{c}\text { Posicionamento em relaçăo à teoria de inserçăo da } \\
\text { arquitetura }\end{array}$ \\
\hline Visão desenvolvimentista do planejamento; & Objeto concebido de modo isolado; \\
\hline Visão tecnicista e apolitica do planejamento; & $\begin{array}{l}\text { Objeto concebido a partir de uma postura estratégica em } \\
\text { relação ao seu entorno, ou seja, com intençăo de modificar } \\
\text { o local; }\end{array}$ \\
\hline $\begin{array}{l}\text { Visāo politizada do planejamento acompanhada de } \\
\text { tentativas de maior eficiência e menor distorção dos } \\
\text { instrumentos; }\end{array}$ & $\begin{array}{l}\text { Objeto concebido a partir de postura contextualista, ou } \\
\text { seja, com intençâo de absolver e potencializar sua } \\
\text { peculiaridade; }\end{array}$ \\
\hline $\begin{array}{l}\text { Visão crítica do planejamento enquanto instrumento de } \\
\text { dominação, acompanhada do reconhecimento de } \\
\text { insurgências. }\end{array}$ & $\begin{array}{l}\text { Objeto tático, exploratório, que articula e potencializa } \\
\text { situaçōes do entorno sem unidade funcional, formal ou } \\
\text { técnica. }\end{array}$ \\
\hline
\end{tabular}

Quadro 3 | Posturas de posicionamento dos alunos em relação à teoria urbana e de inserção da arquitetura. Fonte: Elaborado pelo autor.

Sobre o segundo conjunto de desafios, a elaboração do plano urbano de intervenções ou produto equivalente proposto e justificado pelo aluno, lida com um amplo escopo definido no plano de aula da disciplina, mas vem produzindo estudos fragmentados e excessivamente generalistas dos subtemas, não resultando em uma leitura articulada do lugar. Considerando as observações formuladas pelos professores ao longo do extenso volume de bancas de avaliação, foi possível listar no Quadro 4 seis grupos de expectativas sobre o escopo dessa etapa de trabalho. 


\begin{tabular}{|c|c|c|}
\hline & Situaçāo urbana existente & Situaçāo urbana proposta \\
\hline $\begin{array}{l}\text { Uso e ocupação } \\
\text { do solo }\end{array}$ & 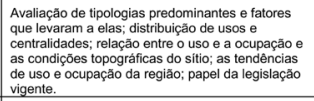 & $\begin{array}{l}\text { Espera-se que o Plano Mestre articule os } \\
\text { instrumentos urbanos adequados para transformar } \\
\text { a situação existente em situaçăo proposta (tipo de } \\
\text { uso, parâmetros de ocupação, operaçắo urbana, } \\
\text { área de diretrizes especiais, intervençő́es no } \\
\text { parcelamento etc.): }\end{array}$ \\
\hline População & 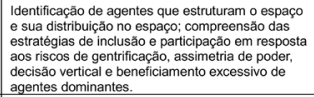 & $\begin{array}{l}\text { Articulação entre as propostas e as coalizões de } \\
\text { forças observadas, buscando a construçăo de } \\
\text { prognóstico realista em relação a proposiçăo de } \\
\text { novos zoneamentos, centralidades, equipamentos } \\
\text { urbanos, locais de uso público, novos modais de } \\
\text { transporte, entre outros. }\end{array}$ \\
\hline $\begin{array}{l}\text { Mobilidade } \\
\text { urbana }\end{array}$ & $\begin{array}{l}\text { Avaliação da estrutura existente considerando a } \\
\text { hierarquia viária, os principais fluxos de cada } \\
\text { modal de transporte, a articulação regional e local, } \\
\text { a micro acessibilidade, a percepcáa dos } \\
\text { moradores sobre o tema e as politicas públicas } \\
\text { existentes. }\end{array}$ & $\begin{array}{l}\text { Possibilidade de abertura ou fechamento de vias, } \\
\text { viadutos e trincheiras, alteraçăa de sentido de } \\
\text { circulação e propostas de diferentes modais. } \\
\text { Recomenda-se justificar os custos e beneficios e } \\
\text { entender os impactos das decisões. }\end{array}$ \\
\hline Meio Ambiente & $\begin{array}{l}\text { Avaliação dos problemas e potenciais ambientais } \\
\text { da área de estudo (topografia, hidrografia, } \\
\text { insolaçăao, ventilaçăo, etc.) e a relaçăo destes com } \\
\text { a dinămica urbana. }\end{array}$ & $\begin{array}{l}\text { Articular as soluçōes ambientais com as } \\
\text { intervençōes urbanas e arquitetônicas (parques, } \\
\text { recuperaçăo de encostas e nascentes, preservaçăo, } \\
\text { permeabilidade do solo, soluçōes de drenagem, } \\
\text { arborizaçāo de vias etc.); }\end{array}$ \\
\hline $\begin{array}{l}\text { Espaços livres de } \\
\text { uso público }\end{array}$ & $\begin{array}{l}\text { Compreensão da distribuição regional dos } \\
\text { espaços, da forma pelas quais são apropriados } \\
\text { pela população da área e dos equipamentos, } \\
\text { mobiliários, arborizaçăa, iluminaçăa, acessibilidade } \\
\text { do espaço. }\end{array}$ & $\begin{array}{l}\text { Entender a proposta como estrutura complementar } \\
\text { e potencializar sua articulação com a vida cotidiana } \\
\text { do bairro. Projetar estruturas de boa ambiência } \\
\text { urbana, atenta aos fluxos de pedestres e } \\
\text { facilitadoras do convivio }\end{array}$ \\
\hline Edificaçōes & $\begin{array}{l}\text { Identificar locais potenciais de inserçăo do objeto } \\
\text { arquitetônico (ou equivalente) incluindo a } \\
\text { compreensão das condicionantes projetuais } \\
\text { definidas pelo entorno. Compreensão do impacto } \\
\text { da edificaçăa e sua articulaçåao com o local. }\end{array}$ & $\begin{array}{l}\text { Diretrizes para a intervençâo a ser desenvolvida em } \\
\text { escala arquitetônica, incluindo proposiçăo de } \\
\text { programa de atividades compativel como o tempo } \\
\text { de projeto e com as demais diretrizes do plano de } \\
\text { propostas. }\end{array}$ \\
\hline
\end{tabular}

Quadro 4 | Grupos de expectativas presentes nas bancas de avaliação sobre o escopo do Plano Mestre. Fonte: Elaborado pelo autor.

O conjunto demasiadamente ambicioso de expectativas, dificilmente compatibilizado por um único projeto, mas que permite um amplo leque de possibilidades de atendimento à demanda inicial da disciplina, termina por ressaltar a opção conceitual inicial do aluno e sua capacidade de construir uma argumentação coerente ao longo do projeto. Por outro lado, amplia o grau de incerteza dos alunos e abre espaço para conflitos e insatisfação em relação aos processos de orientação e, sobretudo, avaliação.

Sobre o terceiro conjunto de desafios, o projeto do espaço urbano do entorno imediato demanda do aluno a definição 
da geometria das vias, pontos de travessia, desenho das calçadas e dos acessos ao projeto de edificação, quando existente. Espera-se nas áreas públicas a compatibilidade entre a dimensão da área e o seu programa de usos, conformando ambientes que possibilitem a apropriação e direcione os fluxos principais, com qualidade e segurança para o pedestre, o ciclista, o tráfego de veículos e demais modais de transporte. Espera-se, também, a solução dos níveis de altimetria do espaço externo, a previsão de taludes, arrimos, rampas, passarelas e escadas, bem como a distribuição do mobiliário urbano de maior relevância (ponto de ônibus, bicicletário, banheiro público, entre outros). Conforme apontado anteriormente, o principal desafio vem sendo o hiato conceitual e instrumental observado nesta etapa e escala de projeto, gerando soluções inadequadas ou burocráticas, ou seja, que apenas reproduzem as normas e diretrizes institucionais.

Finalmente, sobre a intervenção na escala arquitetônica, espera-se resposta às diretrizes elaboradas em relação ao programa de usos, inserção urbana e efeito desejado na área de inserção. Caso seja uma edificação, seu projeto deve resolver a setorização e dimensionamento dos espaços interiores, circulações verticais, definição de acessos e fluxos, solução do volume, da cobertura e do sistema estrutural com nível de detalhamento de anteprojeto. No caso de não ser uma edificação, pode-se acordar com os 
professores um produto equivalente em complexidade, o que inclui, por exemplo, detalhamento de módulos de ocupação tática dos espaços públicos ou privados, material de interface com a população, mapeamento de redes e planos de ação, propostas de projeto-pesquisa, entre outros.

Como conclusão parcial, pode-se dizer que as situações descritas acima revelam a grande dificuldade em transpor uma opção conceitual para o projeto da forma urbana e arquitetônica no curto espaço de tempo da disciplina. No entanto, foram observadas situações em que, diante da dificuldade de articulação de conteúdo, o aluno opta por atender as demandas da disciplina de modo fragmentado e pontual, cumprindo os ritos de avaliação e entrega de produtos sem avançar na integração entre edifício e espaço urbano, reforçando uma postura de projeto e uma predisposição de tratar as questões urbanas e de inserção local como limitadores do projeto arquitetônico. Na prática profissional, obviamente, essa transposição se torna ainda mais complexa, incluindo agentes, custos, determinações e imprevistos diversos, que tendem a afastar ainda mais o ofício do "arquiteto de prancheta" do planejador urbano. Por isso, mais do que problematizar as limitações e constrangimentos dessa transposição, cabe entender como os pressupostos da formação e prática de projeto contribuem para reproduzir as condições contrárias ao vetor propositivo delineado nesta seção, tema tratado a seguir. 


\section{O papel do habitus e a necessária revisão dos pressupostos de projeto}

O referencial teórico-metodológico desenvolvido pelo sociólogo Pierre Bourdieu em torno do conceito de campo de poder busca o desvelamento da estrutura das relações sociais que orienta determinada prática. $\mathrm{O}$ autor descreve a desigual distribuição de diferentes tipos de capitais entre agentes e o modo como a disputa interna de cada campo de poder se orienta pela predisposição desses agentes para essa disputa. Essa predisposição, ou padrão de reação, compõe o que o autor chama de habitus que, de modo articulado à posição social do agente no campo, estrutura as "potencialidades inscritas nos corpos dos agentes e na estrutura das situações nas quais eles atuam" (BOURDIEU, 2004, p.10).

Ao longo da análise dos Grandes Projetos Urbanos, foi observado que a atuação de urbanistas e arquitetos visava, acima de tudo, dar legitimidade cultural ao projeto. Esse poder de legitimidade é mantido por meio de um ciclo: o agente oferece capital cultural para legitimar o GPU; quanto maior o número de GPU a que o agente se associa, maior sua visibilidade e maior seu capital cultural objetivado (projetos realizados); o que torna a escolha mais eficaz para futuras legitimações de GPU. O capital cultural objetivado garante a estabilidade do agente no campo e a manutenção 
do círculo de privilégios (STEVENS, 2003), mas necessita ainda ser complementado por: (a) capitais culturais institucionais, obtidos por reconhecimento, incluindo títulos e premiações, que ampliam a visibilidade do agente e favorecem a imposição de sua representação da realidade sobre o campo; (b) capitais culturais corporificados, reforçados pelo status social desse agente e sua capacidade de transitar em círculos culturais e técnicos, reafirmando uma assinatura ou grife de fácil reconhecimento e absorção pelos demais agentes do campo; e (c) capitais culturais sociais, que representa o bom trânsito em redes sociais de alto capital político, o que favorece informações privilegiadas, capacidade de influenciar decisões, tradução de políticas em projetos de interesse, maior possibilidade de construir consensos e ampliação dos atributos técnicos e artísticos.

O papel dos arquitetos urbanistas nesse campo de poder e o modo como orientam seus interesses para a acumulação dos capitais culturais apontados consolidam sua predisposição de interação com os demais agentes que, entre outros efeitos, define sua prática de projeto e, de modo mais específico, as expectativas em relação ao diálogo entre o objeto projetado e a dinâmica de forças que orienta a produção do espaço urbano. Três aspectos precisam ser destacados nessa prática: (a) a concepção do objeto como forma completa (cuja coerência independe do local de inserção) e fechada (impermeável a modificações futuras, ou 
seja, entendida como algo concluído e não em processo de contínua adaptação ao meio); (b) o carater autoral do projeto entendido como algo arbitrado e condicionado pela visão de mundo do profissional e não pela resposta a condicionantes do lugar e dos agentes que o produzem e vivenciam; e (c) o alinhamento com agentes dominantes no campo de produção do espaço urbano (donos de terra, incorporadoras, empreiteiras, políticos, investidores, entre outros) em detrimento de reconhecimento de outros processos de produção do espaço ou insurgências, resistências e outras agendas. Trata-se, no entanto, de uma prática dissonante do discurso, no qual arquitetos e urbanistas oscilam entre duas posturas. A primeira, assumindo um argumento de "ciência pura" da profissão, no qual os atributos técnicos e formais são deslocados das determinações externas do objeto projetado (economia e política, principalmente). A segunda, um argumento de "ciência escrava" da profissão, em que o profissional internaliza as determinações e assume postura de mediação ou conformação com o papel do objeto projetado. Nos dois casos, caracteriza o habitus de projeto a observação formulada por Webster (2010) para quem:

Um dos resultados deste processo de socialização e aculturamento é que os arquitetos passam a enxergar o mundo de modo refratado, ou interpretado, a partir de lentes arquitetônicas e como consequência eles geralmente se tornam frustrados ou intolerantes a outras 
visões (público geral, construtores, pesquisas quantitativos etc.) que enxergam o mundo de modo diferente" (WEBSTER, 2010, p.25).

Nas bancas e nos produtos realizados ao longo da disciplina PIAU, esse habitus se materializa e se estrutura a partir do interesse dos estudantes em acumular os diferentes capitais culturais apontados anteriormente. O Quadro 5 retoma as posturas conceituais descritas anteriormente e constrói, orientado por observações qualitativas, a seguinte correspondência entre as opções conceituais do aluno e a estratégia que ele utiliza para ampliar seus capitais culturais, prática que consolida ao mesmo tempo em que é orientada pelo seu habitus.

\begin{tabular}{|c|c|c|}
\hline $\begin{array}{l}\text { Tipos de capitais } \\
\text { culturais }\end{array}$ & Estratégia adotada para acumulaçāo & Como afeta e è afetado pelo habitus \\
\hline Capital cultural objetivado & $\begin{array}{l}\text { Ênfase no produto final e năo no processo, o } \\
\text { que induz produçãa de arquitetura isolada ou } \\
\text { estratégica. No outro extremo, produtos de } \\
\text { carater experimental privilegiam estética } \\
\text { gráfica em detrimento de conteúdo. Plano } \\
\text { urbano com diretrizes assume forma de } \\
\text { Master Plan, incorporando diagramas e } \\
\text { imagens proximas às grandes operaçōes } \\
\text { urbanas. }\end{array}$ & $\begin{array}{l}\text { Predisposição para construção de portifólio } \\
\text { com quantidade máxima de projetos, } \\
\text { preferencialmente alinhado com produçăo de } \\
\text { mercado e/ou de arquitetura contemporânea } \\
\text { espetacularizadas. Direcionamento para } \\
\text { concursos, publicaçōes ou viabilização de } \\
\text { projetos. }\end{array}$ \\
\hline $\begin{array}{l}\text { Capital cultural } \\
\text { institucional }\end{array}$ & $\begin{array}{l}\text { Entre os três tipos de capitais analisados, é o } \\
\text { de menor interesse dos alunos, acionado } \\
\text { somente quando existe vínculo pessoal direto } \\
\text { do aluno com instituição pública próxima ao } \\
\text { tema. A pouca valorizaçăao desse capital } \\
\text { colabora para a pouca discussão sobre } \\
\text { normatização e viabilidade das intervençōes, } \\
\text { bem como para a alienaçăo em relação aos } \\
\text { problemas urbanos mais próximos da } \\
\text { realidade institucional. }\end{array}$ & $\begin{array}{l}\text { Predisposiçăo tanto para investigaçōes } \\
\text { acadêmicas e maior alinhamento a linha de } \\
\text { pesquisa dos professores como para diálogos } \\
\text { institucionais fora da academia (consultorias, } \\
\text { setores da administraçăo pública, etc.). }\end{array}$ \\
\hline $\begin{array}{l}\text { Capital cultural } \\
\text { corporificado }\end{array}$ & $\begin{array}{l}\text { Capital que, sobretudo nos cursos de } \\
\text { arquitetura, está atrelado ao capital social e à } \\
\text { possibilidade de articular redes por meio da } \\
\text { formação de grupos de afinidade em relação à } \\
\text { disciplina, mas não exclusivamente. Observa- } \\
\text { se tendenncia à polarizaçăo entre visões } \\
\text { desenvolvimentistas ou institucionais do } \\
\text { planejamento e visóes criticas e insurgentes } \\
\text { em relaçāo ao planejamento; ou sobre oo papel } \\
\text { da arquitetura; ou ainda revisão da prática } \\
\text { projetual e do instrumental para sua } \\
\text { realização. }\end{array}$ & $\begin{array}{l}\text { Predisposição para polarização entre (a) } \\
\text { postura alinhada com prática profissional, } \\
\text { incluindo comportamento corporativo e } \\
\text { reproduçẫo de práticas profissionais; e (b) } \\
\text { postura vanguardista e alinhamento com } \\
\text { temas emergentes na academia e campo } \\
\text { cultural. }\end{array}$ \\
\hline
\end{tabular}

Quadro 5 | Relação entre a aquisição de capitais e consolidação do habitus do aluno. Fonte: Elaborado pelo autor. 
Finalizando, pode-se aferir, a partir do que foi discutido, que a integração entre projeto de arquitetura e espaço urbano passa pela combinação entre: (a) uma ampla (e irrealista) integração conceitual e instrumental a ser compatibilizada por meio de currículo generalista de formação profissional; e (b) pela compreensão dos elementos que constituem a afirmação de um habitus de projeto da forma urbana e arquitetônica. Tal como se apresenta, foram identificados diversos riscos de fragmentação e hiatos no primeiro item e um conjunto de pressupostos que alimentam, em vez de reverter, a ruptura disciplinar no segundo. A necessária reversão desse ciclo de formação requer experimentações sobre a ampliação das estratégias de projeto da forma urbana e arquitetônica e da compreensão da produção do espaço urbano, conformando um novo vetor propositivo para a produção de uma cidade mais justa.

Nesse sentido, intervenções orientadas pela herança modernista de formas fechadas e burocráticas (HOLSTON, 1996), recentemente alinhadas com a frenética lógica de acumulação e sua tendencial produção de "cidades quebradiças" (SENNET, 2006), precisa dar lugar a experimentos projetuais alinhados à apreensão das caraterísticas e dinâmicas do lugar (MASSEY, 2009). Sennet (2006) defende a articulação entre a compreensão do que chama de projeto de formas incompletas (aquelas que não se sustentam sem seu lugar de inserção); territórios de passagem (que 
possuem porosidade social que possibilitem o conflito e a diversidade); e incorporação das narrativas dissonantes e possibilidades de contínua mutação do sistema de objetos e eventos. O instrumental de formação, por sua vez, assim como o referencial propositivo, precisa incorporar, discutir e avançar sobre os limites da representação e normatização, incorporando métodos diagramáticos, cartografias, inserção de atores locais, novas interfaces tecnológicas e de informação, entre outros. Desse modo, a rigidez dos produtos e métodos de avaliação precisa incorporar a ampliação do espaço dos possíveis (BOURDIEU, 1996) no campo do projeto de arquitetura e urbanismo, possibilitando e articulando novos métodos de leitura do lugar e novas reações e propostas à sua produção para além, inclusive, do irreal monopólio do arquiteto urbanista sobre essa produção.

\section{Referências}

BOURDIEU, Pierre. Razões Práticas: Sobre a teoria da ação. Campinas: Papiros, 1996.

BOURDIEU, Pierre. Os usos sociais da ciência: por uma sociologia clínica do campo científico. São Paulo: Ed. UNESP, 2004.

BRASIL. Ministério da Educação. Conselho Nacional de Educação. Resolução $N^{\circ}$ 6, de 2 de fevereiro de 2006. Institui as Diretrizes Curriculares Nacionais do curso de graduação em Arquitetura e Urbanismo e dá outras providências, 2006.

FREITAS, D. M. Desvelando o campo de poder dos Grandes Projetos Urbanos da Região Metropolitana de Belo Horizonte. 2016. Tese (Doutorado) - Programa de Pós Graduação em Arquitetura e Urbanismo - NPGAU - Escola de Arquitetura da UFMG, Belo Horizonte. 
HOLSTON, J. Espaço da cidadania insurgente. Revista do IPHAN, Brasília, n. 24, p. 243-254, 1996.

MASSEY, D. Pelo espaço: uma nova política da espacialidade. Rio de Janeiro: Bertrand Brasil, 2009

SENNET, R. Open city. Disponível em <https://lsecities.net/media/objects/articles/the-open-city/en-gb> Acesso em 01 maio 2017.

STEVENS, G. O círculo privilegiado: fundamentos sociais da distinção arquitetônica. Brasília: Editora da Universidade de Brasília, 2003.

THIRY-CHERQUES, Hermano Roberto. Pierre Bourdieu: a teoria na prática. Revista de Administração Pública, Rio de Janeiro. n. 40, p. 27-55, jan./fev. 2006.

WEBSTER, H. Bourdieu for Architects (Thinkers for Architects). London: Routledge, 2010. 